\title{
Melatonin Interaction Resulting in Severe Sedation
}

Brian C. Foster ${ }^{1 *}$, Kosta Cvijovic ${ }^{2,3}$, Heather S. Boon ${ }^{2}$, Teresa W. Tam ${ }^{1}$, Rui Liu ${ }^{1}$, Mano Murty ${ }^{4}$, Duc Vu ${ }^{4}$, Walter Jaeger ${ }^{3}$, Ross T. Tsuyuki ${ }^{5}$, Joanne Barnes ${ }^{6}$, Sunita Vohra ${ }^{7}$

${ }^{1}$ Faculty of Medicine, University of Ottawa, Ottawa, Ontario; ${ }^{2}$ Leslie Dan Faculty of Pharmacy, University of Toronto, Toronto, Ontario; ${ }^{3}$ Department of Clinical Pharmacy, University of Vienna, Vienna, Austria; ${ }^{4}$ Marketed Health Products Directorate, Health Canada, Ottawa, Ontario; ${ }^{5}$ Faculty of Medicine and Dentistry, University of Alberta, Edmonton, Alberta; ${ }^{6}$ School of Pharmacy, University of Auckland, Auckland, New Zealand; ${ }^{7}$ CARE Program, Department of Pediatrics, Faculty of Medicine and School of Public Health, University of Alberta, Edmonton, Alberta.

Received, March 31, 2015; Revised, April 13, 2015; Accepted, April 15, 2015; Published, April 21, 2015

\begin{abstract}
Purpose. Natural health products (NHPs), including melatonin, are widely used products. Despite the widespread assumption that all NHPs are safe, they contain pharmacologically active substances and can therefore have adverse effects and/or interact with pharmaceuticals. Objective: To investigate the mechanism underlying NHP interactions identified through the Pharmacy SONAR active surveillance study. Methods: Active surveillance was undertaken in community pharmacies to identify adverse events in patients who had recently taken NHPs together with conventional pharmaceuticals. For suspected NHP-pharmaceutical interactions, the possible mechanism of action was explored by in vitro analysis of samples of different products to identify cytochrome P450 enzyme (CYP) inhibition potential. Results: Active surveillance identified a 19year-old male taking citalopram, nortriptyline and oxycodone concomitantly and who experienced severe sedation when melatonin was added to this regimen. In vitro analysis involving several melatonin products showed product-dependent inhibition of CYP1A2, CYP2C19 and CYP3A7. Conclusion: The adverse event was likely due to a primary pharmacokinetic interaction between melatonin and citalopram; although mechanistically, interactions affecting cytochrome P450-mediated metabolism may have occurred with all of these health products. A pharmacodynamic interaction may also be possible, but beyond the capacity of this study to establish.
\end{abstract}

Key words: Melatonin, citalopram, nortriptyline, oxycodone, drug interaction.

This article is open to POST-PUBLICATION REVIEW. Registered readers (see "For Readers") may comment by clicking on ABSTRACT on the issue's contents page.

\section{INTRODUCTION}

Although generally regarded as safe by the public (1-3), there is growing evidence that natural health products (NHPs) can have clinically significant adverse effects and interactions with each other as well as with other health products which includes biologics, drugs, NHPs, over-the-counter products and traditional medicines (4-6). A formidable challenge for pharmacovigilance of NHPs is the under-reporting of suspected adverse drug reactions associated with these products $(7,8)$. The Pharmacy Study Of Natural health product Adverse Reactions (SONAR) is a multi-centre study assessing the feasibility of a community pharmacy-based active surveillance system to identify adverse reactions related to NHPs $(9,10)$. The study identified a patient who presented with severe sedation after intake of melatonin with two antidepressants (citalopram and nortriptyline) and one opioid analgesic (oxycodone). As plasma samples had not been obtained for the determination of active substances, a mechanism for the interactions could not be determined. Melatonin is widely used by adults as a sleep aid and in the treatment of sleep disorders. A recent report has shown that the use of this product in children is increasing (11).

Correspondence Author: Brian C. Foster, Ph.D., Faculty of Medicine, Department of Cellular and Molecular Medicine, University of Ottawa, Ottawa, ON, K1H 8M5, Canada. Email: bfoste2@uottawa.ca. 
Melatonin acts like a selective estrogen enzyme modulator inhibiting expression and activity of P450 aromatase, estrogen sulfatase and type 1, 17 $\beta$ hydroxysteroid dehydrogenase, but stimulating estrogen sulfotransferase (12). It is generally regarded as safe (13), with the most common adverse effects being fatigue, dizziness, headache, and irritability; however, in clinical trials, the incidence of these is often similar in the melatonin and placebo groups, and these effects may be related to jet-lag, a common use for melatonin, rather than to melatonin itself $(14,15)$.

Inter- and intra-individual differences in the expression and function of drug metabolizing enzymes such as cytochrome P450 (CYP) and transport proteins such as the efflux transporter, Pglycoprotein can result in variance to the safety and efficacy of therapeutic products using these pathways. Citalopram is metabolised by cytochrome P450 2C19 and CYP2D6 (16-18), nortriptyline by CYP2D6 and CYP1A2 (19) and oxycodone by CYP2D6 and CYP3A (20). One of the most common adverse effects of citalopram is somnolence, a state of near-sleep, a strong desire for sleep, or sleeping for unusually long periods (17). Severe drowsiness was listed as a potential adverse effect in an oxycodone product monograph.

Melatonin is selectively metabolized by CYP1A2 to 6-hydroxymelatonin with a minor contribution from CYP 2C19, CYP1A1 and CYP1B1; and subsequent conjugation with sulfate or glucuronide $(21,22)$. Melatonin $(3-300 \mu \mathrm{M})$ inhibited CYP1 enzymes by mixed inhibition, with apparent K(i) values (mean \pm S.E.M.) of $59 \pm 1$, CYP1A1; $12 \pm 1$, CYP1A2; $14 \pm 2$ CYP1B1; and $46 \pm 8 \mu \mathrm{M}$ human hepatic microsomes (23). A second major metabolite, $\mathrm{N}$-acetylserotonin is formed by O-demethylation (24). CYP2C9 has also been reported to metabolize melatonin (25). Other melatonin metabolites include 3-hydroxymelatonin, $\mathrm{N}(1)$-acetyl-N(2)-formyl-5-methoxykynuramine and its metabolite, N(1)-acetyl-5methoxykynuramine. Melatonin is deacetylated, at least in pineal gland and retina, to 5methoxytryptamine. Many of the melatonin metabolites, which may appear in elevated concentrations after melatonin administration, possess biological or pharmacological properties, including $\mathrm{N}$-acetylserotonin, 5-methoxytryptamine and some of its derivatives, and especially the 5methoxylated kynuramines $(26,27)$. Rat mitochondrial CYP 2C6 and 3A has also been associated with melatonin metabolism (24).

Melatonin increased the side effects and antiepileptic activity of carbamazepine but did not affect plasma concentration (28). A single oral dose of fluvoxamine, an inhibitor of CYP1A2, increases nocturnal serum melatonin concentrations in healthy subjects (29). Furthermore, the results indicate that there is a potential for interaction with drugs metabolised by CYP1A2 both at physiological levels and after oral administration of melatonin, while CYP2C19 and CYP2C9 are assumed to be less important. In a small 7 subject clinical study, $40 \mathrm{mg}$ citalopram did not affect the metabolism of physiological melatonin over a 20 hour period immediately following a single dose (30). Citalopram is a known substrate for CYP2C19 and has been shown to increase the urinary excretion of 6-sulphatoxymelatonin, presumably through the decreased metabolism of melatonin to acetylserotonin (24).

\section{MATERIALS AND METHODS}

\section{Active Surveillance}

This SONAR study received ethical approval from both the University of Toronto and the University of Alberta. Detailed methods have been presented previously $(9,10)$ In brief, adverse events were identified in a community pharmacy where participating pharmacists and pharmacy staff were systematically asking patients collecting prescriptions for conventional medicines whether they had recently been taking NHPs such as herbal medicines, vitamins, minerals or other supplements together with prescription medications and whether they had experienced an unwanted or unexpected effect. Where adverse events were identified, the study team then obtained informed written consent from the patient prior to an in-depth guided telephone interview. The interview form was developed based on information that is required for the adverse event reporting forms of Health Canada (31), the USA Food and Drug Administration (32), and the European Medicines Agency (33), as well as the information needed to complete assessment of case reports using the Naranjo (34) and Horn (35) causality scales and WHO causality assessment criteria (36) for suspected adverse drug reactions. Information gathered included: a description of the adverse event; timing of the onset and resolution; 
treatment; start and stop dates for all medicines (including NHPs) the patient was taking; detailed information about each medicine such as name, brand, dosage, lot number, and reason for use; medical history; patient interactions with health care professionals; any adverse event reports made to health authorities (and by whom). An adjudicating committee comprising a clinician, medicinal chemist, and an expert in NHPs then assessed the report for causality based on the Naranjo algorithm, Horn algorithm, and WHO causality assessment criteria.

Table 1. Melatonin products examined for their potential to affect cytochrome P450-mediated metabolism. All products were in date at time of testing.

\begin{tabular}{|c|c|}
\hline NRP \# & Product \\
\hline 405 & $\begin{array}{l}\text { NOW FOODS Melatonin } 3 \mathrm{mg} \text {; NPN N/A, } \\
\text { Lot } 83255 \text { 1073321, Form - capsule. }\end{array}$ \\
\hline 406 & $\begin{array}{l}\text { Webber Naturals Easy Dissolve Sublingual } \\
\text { Melatonin } 3 \mathrm{mg} \text {; NPN 80000847, Lot } \\
557010, \text { Form -tablet. }\end{array}$ \\
\hline 407 & $\begin{array}{l}\text { Natures Harmony Sleep Tight Melatonin } 3 \\
\text { mg; NPN 80000737, Lot C080, Form - } \\
\text { capsule }\end{array}$ \\
\hline 408 & $\begin{array}{l}\text { Swiss Natural Sources Timed Release } \\
\text { Melatonin Plus with Vitamin } B_{6} ; \quad \text { NPN } \\
\text { 800005067, Lot } 26624 \text {, Form - tablet }\end{array}$ \\
\hline 414 & $\begin{array}{l}\text { Naka Melatonin } 3 \mathrm{mg} \text {; NPN 80001382, Lot } \\
\text { 28448, Form - capsule }\end{array}$ \\
\hline 440 & $\begin{array}{l}\text { Naka Melatonin } 3 \mathrm{mg} \text { (NRP } 440 \text { came from } \\
\text { the patient); NPN 80001382, Lot } 26417 \text {, } \\
\text { Form - capsule. }\end{array}$ \\
\hline
\end{tabular}

\section{Mechanistic Studies}

In order to further examine the potential interaction, mechanistic studies where initiated with a sample of the patient's melatonin, together with samples and another lot of the same product, and other melatonin products, were obtained (Table 1). Inhibition assays were undertaken on all samples using recombinant human CYP1A2, CYP2C19, CYP2D6, CYP3A4, CYP3A7 and CYP19 following a published procedure that detects the quantity of metabolized substrate by fluorescence in a 96-well plate format (37). A representative sampling of melatonin tablets were finely crushed and used to make a $50 \mathrm{mg} / \mathrm{ml} 60 \%$ methanolic stock extract. A $2 \mu \mathrm{L}$ aliquot of this extract was used for inhibition testing of the CYP isozymes. Citalopram (Sigma) and nortriptyline (Sigma) were also examined to determine their inhibitory potential towards CYP1A2, CYP2C19, CYP2D6, and CYP19. These drugs were dissolved in methanol and were examined at a concentration $(200 \mathrm{ng} / \mathrm{ml})$ that exceeds the average therapeutic plasma concentrations of both these anti-depressants (38, 39). The positive controls used were $10 \mu \mathrm{g} / \mathrm{ml}$ furafylline (CYP1A2), $13.7 \mu \mathrm{g} / \mathrm{ml}$ tranylcypromine (CYP2C19), $648 \mathrm{ng} / \mathrm{ml}$ quinidine (CYP2D6), 531 $\mathrm{ng} / \mathrm{ml}$ ketoconazole (CYP3A4, 3A7), and $124 \mathrm{ng} / \mathrm{ml}$ bifonazole (CYP19). Oxycodone is a controlled substance and could not be examined in our facilities. Each sample was tested in triplicate and the procedure was repeated at least once. The percent inhibition of each extract or antidepressant was calculated relative to the CYP activity with its respective vehicle control.

\section{Metabolism Studies}

Citalopram, nortriptyline and melatonin were incubated with CYP1A2, CYP2C19 and 50-mixed gender pooled human liver microsome (HLM) were purchased from BD Biosciences (Mississauga, ON, Canada) with NADPH in $0.1 \mathrm{M}$ PBS buffer at $37^{\circ} \mathrm{C}$ for 30-60 min (40). The incubation matrix was divided into 2 parts. One part was mixed with equal amount of methanol to de-nature the protein and was then analyzed by HPLC-DAD. The other part went through a liquid to liquid extraction with ethyl acetate and then analyzed by UPLC-MS. Each study was run in triplicate and the studies were repeated once.

\section{RESULTS}

\section{Active Surveillance}

Active surveillance identified a 19-year-old male patient of Canadian aboriginal origin, weighing 350 lbs with a height of 6' '1", who presented with severe sedation, starting in November 2007 and ending in January 2008. The patient's medical history included depression, neuropathic pain and delayed sleep phase disorder. The patient was a non-smoker and reported to never consume alcohol as they were contraindicated with his medications. At the onset of the event, the patient was taking three prescription medications: citalopram $40 \mathrm{mg}$ daily since September 2007 for depression; nortriptyline $25 \mathrm{mg}$ three times daily since July 2007 for 
depression and neuropathic pain; and oxycodone (OxyContin $($ ) $40 \mathrm{mg} \mathrm{1-2} \mathrm{tablets} \mathrm{twice} \mathrm{daily} \mathrm{since}$ July 2007 for neuropathic pain. At the onset of the event, the patient started taking melatonin (NAKA ®) $3 \mathrm{mg}$ daily until January 2008 for delayed sleep phase disorder. The patient reported that severe sedation only occurred during the time period when these 3 medications were taken together with melatonin. The sedation improved when melatonin use was discontinued. Discontinuation of oxycodone was required to completely clear the sedation. With melatonin rechallenge, the sedation worsened. The patient consulted with his physician and was directed to discontinue melatonin and, if necessary, oxycodone. Other than drinking coffee and walking to alleviate the sedation, there were no other interventions to treat the adverse event. The patient reported that the adverse event interfered strongly with his ability to perform his daily duties, as it was difficult for him to concentrate on his work. He was not hospitalized at any point. During this time, the patient had no other medical interventions or treatments such as vaccinations, surgery, etc. The patient had not taken melatonin before November 2007. No tests or investigations were performed by the patient's health care professionals as a result of the event.

The interaction was deemed 'possible' to 'likely' related to melatonin based on the adjudication committee criteria from the WHO, Naranjo and Horn assessment tools (34-36). The adjudication hypothesized that the patient's severe sedation may be a combined additive pharmacodynamic interaction where the effects of one drug were changed by the presence of another drug and a pharmacokinetic interaction that affected the processes by which drugs are absorbed, distributed, metabolised and excreted between melatonin and one or more of the prescription drugs, although this putative interaction has not previously been described in the literature. As a result of these findings, the adjudicators recommended in vitro assessment to investigate a possible mechanism for a pharmacokinetic interaction.

\section{Mechanistic Studies}

The products, other than the product used by the patient, NAKA ${ }^{\circledR}$ Melatonin (NRP 440) were not tested for adulterants/contaminants or confirmation for the presence of melatonin. The product label confirmed that it was registered with Health Canada, Natural Health Product Number 80001382. Subsequent tests with this product and related products were conducted prior to their expiry date.

Six melatonin products, all available brands in Toronto and Ottawa, Canada were tested (Table 1). The six melatonin products tested all showed CYP2C19 inhibitory activity, three had similar activity towards CYP3A7, whereas none of the melatonin samples showed marked inhibitory activity against CYP2D6 and CYP3A4 (Figure 1). The two NAKA ${ }^{\circledR}$ brand products (NRP 414 and 440) had similar, but not identical, inhibition profiles. The results with CYP3A4 and 3A7 were consistently lower for NRP 440 than for NRP414. In this initial testing, citalopram did not affect the activity of any of the CYP isozymes studied (Table 2). Similar results were observed with nortriptyline except with CYP2C19. Nortriptyline inhibited more than 56\% of CYP2C19-mediated metabolism relative to the vehicle control (Table 2). Testing was then extended to include melatonin (Table 3) against CYP1A2, 2D6 and 3A4. In this series, isozyme and concentration dependant inhibition was observed for all substances. Melatonin was inhibitorier towards CYP1A2. Nortriptyline affected CYP2D6-mediated metabolism to the greatest extent. Nortriptyline and melatonin had a similar effect on CYP3A4.

\section{Metabolism Studies}

Reported human metabolites of citalopram, nortriptyline and melatonin were not found in the any of the incubation matrices. Recoveries were in excess of about $90 \%$.

Table 2. Inhibition of human recombinant cytochrome P450 (CYP) isozymes by $200 \mathrm{ng} / \mathrm{ml}$ citalopram and nortriptyline nortriptyline $(\mathrm{n}=2$; mean $\pm \mathrm{SD})$.

\begin{tabular}{l|c|c|c|c}
\hline & CYP1A2 & CYP2C19 & CYP2D6 & CYP3A4 \\
\hline Citalopram & $-8.5 \pm 2.1$ & $-2.5 \pm 2.2$ & $-12.2 \pm 0.7$ & $4.7 \pm 2.1$ \\
Nortriptyline & $-3.4 \pm 0.9$ & $56.9 \pm 0.6$ & $-3.6 \pm 1.9$ & $4.3 \pm 0.3$
\end{tabular}


Table 3. Inhibition of human recombinant cytochrome P450 (CYP) isozymes by similar concentrations of citalopram, melatonin and nortriptyline $(\mathrm{n} \geq 2$; mean $\pm \mathrm{SD})$. The range tested covers the range of dosed products.

\begin{tabular}{lclll}
\hline Substance & $\begin{array}{c}\text { Concentration } \\
\text { mM }\end{array}$ & \multicolumn{1}{c}{ CYP1A2 } & \multicolumn{1}{c}{ CYP2D6 } & \multicolumn{1}{c}{ CYP3A4 } \\
\hline Citalopram & 0.5 & $0.69 \pm 8.78$ & $68.93 \pm 3.0$ & $-2.85 \pm 2.70$ \\
& 0.1 & $-1.35 \pm 0.97$ & $30.94 \pm 0.97$ & $-11.59 \pm 6.30$ \\
& 0.01 & $-2.23 \pm 1.69$ & $7.70 \pm 1.69$ & $-1.43 \pm 4.32$ \\
Nortriptyline & 0.5 & $48.19 \pm 1.96$ & $125.32 \pm 1.96$ & $58.21 \pm 1.80$ \\
& 0.1 & $29.39 \pm 1.38$ & $86.35 \pm 1.38$ & $11.70 \pm 4.02$ \\
& 0.01 & $4.68 \pm 6.67$ & $26.65 \pm 6.67$ & $-4.48 \pm 2.57$ \\
Melatonin & & & & \\
& 0.5 & $80.38 \pm 4.01$ & $74.50 \pm 4.01$ & $40.66 \pm 0.43$ \\
& 0.1 & $49.63 \pm 6.73$ & $23.30 \pm 6.73$ & $13.27 \pm 5.08$ \\
& 0.01 & $14.38 \pm 1.28$ & $19.31 \pm 1.28$ & $-6.11 \pm 13.9$ \\
\hline
\end{tabular}

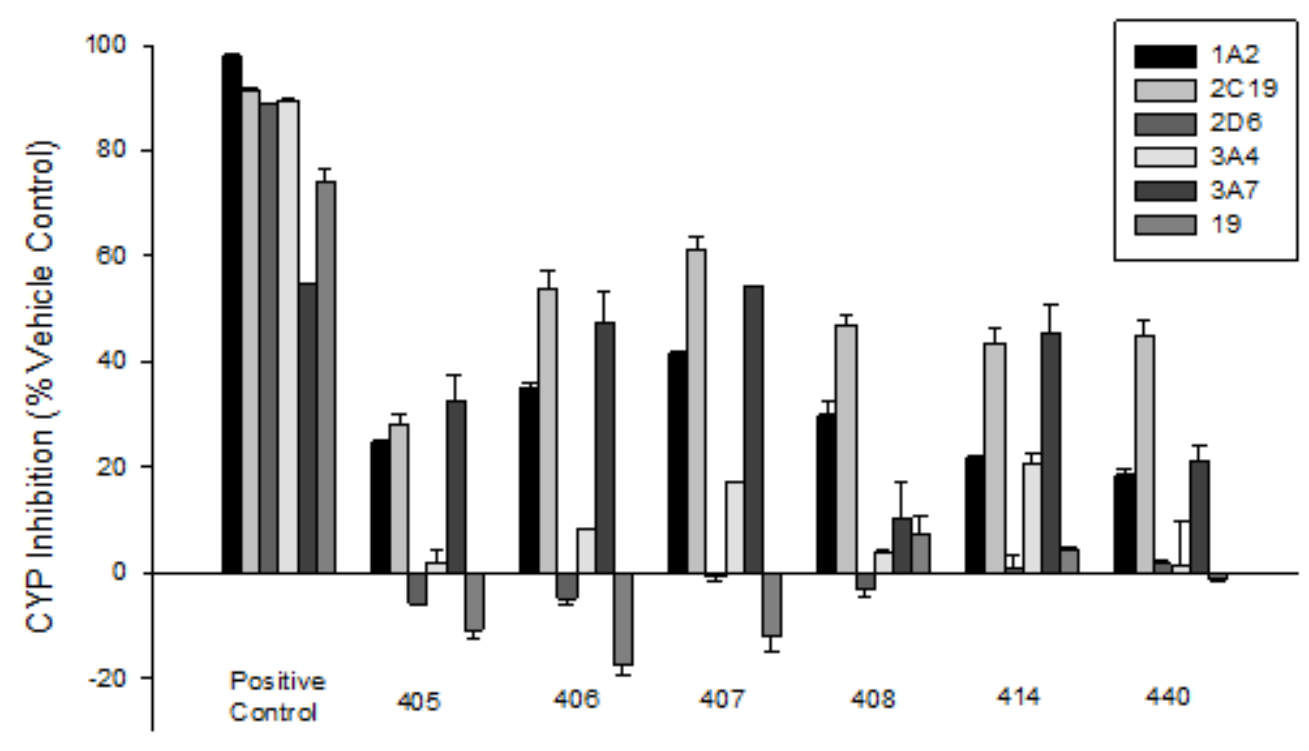

Figure 1. Inhibition of human recombinant cytochrome P450 (CYP) isozymes by various commercial melatonin samples (n $=2$; mean $\pm \mathrm{SD}$ ). The positive controls used were furafylline (CYP1A2), tranylcypromine (CYP2C19), quinidine (CYP2D6), ketoconazole (CYP3A4, 3A7), and bifonazole (CYP19).

\section{DISCUSSION}

Based on the adverse event reported by the patient identified in the active surveillance report, it is likely that both pharmacodynamic and pharmacokinetic interactions between melatonin and one or more of the pharmaceuticals occurred in this patient, which represents a novel interaction not previously reported. Although the underlying depression and sleep disorder may also have caused sedation, the sedation improved upon discontinuation of melatonin and worsened upon rechallenge while all other medications remained constant. It seems probable that the severe sedation reported in this case was related to the addition of the melatonin. An additive pharmacodynamic 
interaction was possible as sedation is a known adverse effect of the three prescription drugs taken by the patient as well as of melatonin. It is noteworthy that the patient reported drinking coffee to counter the sedation, as caffeine has been reported to increase the effects of melatonin (30), hence ingesting coffee might paradoxically have contributed to the sedating effect. Caffeine is a known substrate for CYP1A2 and competitive inhibition would result in less melatonin metabolism with a concomitant increase in activity (24). This underlies the need for detailed reporting of all extrinsic factors in surveillance reports.

In this in vitro test system, our findings demonstrated that the different melatonin products had lot-specific potential to inhibit CYP1A2, CYP2C19, and CYP3A7 isozymes. In vitro assay with authentic material also demonstrated that melatonin could affect CYP2D6- and CYP3A4mediated metabolism. Under these conditions citalopram could affect CYP2D6-mediated metabolism. Nortriptyline had a wider effect than citalopram and could alter CYP1A2-, CYP2C19-, CYP2D6- and CYP3A4-mediated metabolism.

Findings from animal studies contradict the results of our in-vitro experiments. RamírezRodríguez et al. (41) found decreased immobility behaviour in mice treated separately with melatonin $(<14-33 \%)$ and citalopram $(<17-30 \%)$. Additionally, a combination of melatonin and citalopram also decreased immobility $(<22-35 \%)$ in comparison with control mice, reflecting an antidepressant-like effect after 14 days of treatment. This helps underline that in vitro mechanistic information may not always correlate with clinical findings.

The findings in this study are consistent with the known metabolism of citalopram (CYP2C19 and CYP2D6 $(16,42))$, nortriptyline (CYP2D6 and CYP1A2 (19)) and oxycodone (CYP2D6 and CYP3A (20)). Caffeine and nortriptyline inhibition of CYP1A2 is important as melatonin is primarily metabolized by this isozyme (43). Together, all products had the potential to interact with melatonin. Although it is known that melatonin concentrations can increase during therapy (24), the absence of clinical concentrations for these substances in this patient at the time of the adverse events precludes unequivocal conclusions.

This study supports Ma et al. (21) in that melatonin has the potential to strongly inhibit CYP isozymes and can therefore enhance the effects of medications metabolized by this isozyme, including their adverse effects. Furthermore, melatonin seems to also inhibit CYP3A7 activity, which might be relevant in pregnancy, for neonates and infants. Because of the manufacturer and lot differences the 'generally regarded as very safe' (13-15) status given to melatonin needs to be reviewed. This new aspect of its pharmacokinetic properties might impact its safety profile, requiring possibly warranting labelling changes for melatonin products. Health care professionals prescribing or dispensing melatonin should advise caution in patients who are also taking other health products that may either reduce efficacy or enhance risk, including when undertaking activities such as driving, operating heavy machinery.

Future research and extensive pharmacovigilance is required to examine potential melatonin interactions with health products having similar metabolic pathways or capable of causing drowsiness. Health care professionals prescribing or dispensing medications metabolized by CYP2C19 such as citalopram, nortriptyline or oxycodone should advise their patients to use melatonin with caution. Patients choosing to use these medications concurrently with melatonin should be monitored closely for adverse effects.

\section{ACKNOWLEDGMENTS}

Funding was provided in part by the Canadian Institutes of Health Research, Canadian Patient Safety Institute, and Health Canada. S. Vohra also received salary support from Alberta Innovates Health Solutions as a Health Scholar.

\section{CONFLICT OF INTEREST}

The authors have declared that there is no conflict of interest.

\section{REFERENCES}

1. Barnes J, Mills S, Abbot N, Willoughby M, Ernst E. Different standards for reporting ADRs to herbal remedies and conventional OTC medicines: face-toface interviews with 515 users of herbal remedies. Br J Clin Pharmacol, 1998; 45:496-500.

2. Ipsos Reid. Baseline Natural Health Products Survey Among Consumers. 2005. (Accessed May 13, 2009, 
http://www.hc-sc.gc.ca/dhp-

$\mathrm{mps} /$ pubs/natur/eng_cons_survey_e.html).

3. Boon H, Kachan N. Natural Health Product labels: Is More Information Always Better? Pat Ed Counsel, 2007; 68:193-199.

4. Skalli S, Zaid A, Soulaymani R. Drug interactions with herbal medicines. Ther Drug Monit, 2007; 29(6):679-686.

5. Marchetti S, Mazzanti R, Beijnen JH, Schellens JHM. Concise review: Clinical relevance of drugdrug and herb-drug interactions mediated by the ABC transporter ABCB1 (MDR1, P-glycoprotein). Oncologist, 2007; 12:927-941.

6. Tam TW, Liu R, Arnason JT, Krantis A, Staines WA, Haddad PS, Foster BC. Actions of ethnobotanically selected Cree anti-diabetic plants on human cytochrome P450 isoforms and flavincontaining monooxygenase 3. J Ethnopharmacol, 2009; 126:119-126.

7. Barnes J. Pharmacovigilance of herbal medicines: a UK perspective. Drug Safety, 2003; 26(12):829-851.

8. Charrois T, Hill RL, Vu D, Foster BC, Boon HS, Cramer K, Vohra S. Community Pharmacist Survey of Natural Health Product Adverse Events and Drug Interactions. Ann Pharmacother, 2007; 41:11241129.

9. Necyk C, Tsuyuki R, Boon H, Foster B, LeGatt D, Cembrowski G, Murty M, Barnes J, Charrois T, Arnason J, Ware M, Rosychuk R, Vohra S. Pharmacy Study of Natural Health Product Adverse Reactions (SONAR): A cross-sectional study using Active Surveillance in Community Pharmacies to Detect Adverse Events Associated with Natural Health Products and Assess Causality. Br Med J Open, 2014; 4(3). e003431. doi:10.1136/bmjopen2013-003431.

10. Vohra S, Cvijovic K, Boon H, Foster B, Jaeger W, LeGatt D, Cembrowski G, Murty M, Tsuyuki R, Barnes J, Charrois T, Arnason J, Necyk C, Ware M, Rosychuk R. Study of Natural Health Product Adverse Reactions (SONAR): Active Surveillance of Adverse Events Following Concurrent Natural Health Product and Prescription Drug Use in Community Pharmacies. PLoS One, 2012; 7(9). e45196

11. National Center for Complementary and Integrative Health. Children's Use of Complementary Health Approaches. 2015; https://nccih.nih.gov/health/providers/digest/childuse?nav=upd

12. Sanchez-Barcelo EJ, Mediavilla MD, AlonsoGonzalez C, Rueda N. Breast cancer therapy based on melatonin. Recent Pat Endocr Metab Immune Drug Discov, 2012; 6(2):108-116.

13. Seabra ML, Bignotto M, Pinto LR Jr, Tufik S. Randomized, double blind clinical trial, controlled with placebo, of the toxicology of chronic melatonin treatment. J Pineal Res, 2000; 29:193-200.

14. Suhner A, Schlagenhauf P, Johnson R, Tschopp A, Steffen R. Comparative study to determine the optimal melatonin dosage form for the alleviation of jet lag. Chronobiol Int, 1998; 15(6):655-666.

15. Papavasiliou PS, Cotzias GC, Düby SE, Steck AJ, Bell M, Lawrence WH. Melatonin and parkinsonism. JAMA 1972;221(1):88-89.

16. Jeppesen U, Gram LF, Vistisen K, Loft S, Poulsen HE, Brosen K. Dose-dependent inhibition of CYP1A2, CYP2C19 and CYP2D6 by citalopram, fluoxetine, fluvoxamine and paroxetine. Eur J Clin Pharmacol, 1996; 51:73-78.

17. Prescribing Information for Celexa ${ }^{\circledR}$, Forest Pharmaceuticals Inc. http://www.frx.com/pi/celexa_pi.pdf).

18. Stafford RS, MacDonald EA, Finkelstein SN. National Patterns of Medication Treatment for Depression, 1987-2001. Primary Care Companion, J Clin Psych, 2001; 3(6):232-235.

19. Polasek TM, Miners JO. Time-dependent inhibition of human drug metabolizing cytochromes $\mathrm{P} 450$ by tricyclic antidepressants. Br J Clin Pharmacol, 2007; 65(1):87-97.

20. Lalovic B, Kharasch E, Hoffer C, Risler L, LiuChen LY, Shen DD. Pharmacokinetics and pharmacodynamics of oral oxycodone in healthy human subjects: Role of circulating active metabolites. Clin Pharm Ther, 2006; 79(5):461-479.

21. Ma X, Idle JR, Krausz KW, Gonzalez FJ. Metabolism of melatonin by human cytochromes p450. Drug Metab Dispos, 2005; 33(4):489-494.

22. Wang B, Zhou SF. Synthetic and natural compounds that interact with human cytochrome P450 1A2 and implications in drug development. Curr Med Chem, 2009; 16(31):4066-4218.

23. Chang TK, Chen J, Yang G, Yeung EY. Inhibition of procarcinogen-bioactivating human CYP1A1, CYP1A2 and CYP1B1 enzymes by melatonin. J Pineal Res, 2010; 48(1):55-64. doi: 10.1111/j.1600079X.2009.00724.x.

24. Papagiannidou E, Skene DJ, Ioannides C. Potential drug interactions with melatonin. Physiol Behav, 2014, 131:17-24. doi: 10.1016/j.physbeh.2014.04.016.

25. Mo SL, Zhou ZW, Yang LP, Wei MQ, Zhou SF. New insights into the structural features and functional relevance of human cytochrome P450 2C9. Part I. Curr Drug Metab, 2009; 10(10):10751126.

26. Hardeland R. Melatonin metabolism in the central nervous system. Curr Neuropharmacol, 2010; 8(3):168-181. doi: 10.2174/157015910792246244.

27. Galano A, Medina ME, Tan DX, Reiter RJ. Melatonin and its metabolites as copper chelating 
agents and their role in inhibiting oxidative stress: a physicochemical analysis. J Pineal Res, 2015; 58(1):107-116. doi: 10.1111/jpi.12196.

28. Fong SY, Gao Q, Zuo Z. Interaction of carbamazepine with herbs, dietary supplements, and food: a systematic review. Evid Based Complement Alternat Med, 2013; 2013:1-15. doi: 10.1155/2013/898261.

29. Facciolá G, Hidestrand M, von Bahr C, Tybring G. Cytochrome $\mathrm{P} 450$ isoforms involved in melatonin metabolism in human liver microsomes. Eur J Clin Pharmacol, 2001; 56(12):881-888.

30. Von Bahr C, Ursing C, Yasui N, Tybring G, Bertilsson L, Röjdmark S. Fluvoxamine but not citalopram increases serum melatonin in healthy subjects - an indication that cytochrome P450 CYP1A2 and CYP2C19 hydroxylate melatonin. Eur J Clin Pharmacol, 2000; 56(2):123-127.

31. Health Canada Adverse Drug Reaction Reporting Form. 2009; http://www.cma.ca//multimedia/CMA/Content_Ima ges/ePractice_tools/English/Drug_Information/adver se_e.pdf).

32. USA Food and Drug Administration MedWatch Form. 2009; http://www.fda.gov/medwatch/safety/FDA3500_fillable.pdf).

33. European Medicines Agency CIOMS form. 2009, http://www.cioms.ch/cioms.pdf).

34. Naranjo CA, Busto U, Sellers EM, Sandor P, Ruiz I, Roberts EA, Janecek E, Domecq C, Greenblatt DJ. A method for estimating the probability of adverse drug reactions. Clin Pharmacol Ther, 1981; 30(2):239-245.

35. Horn JR, Hansten PD, Chan LN. Proposal for a New Tool to Evaluate Drug Interaction Cases. Ann Pharmacother, 2007; 41:674-680.

36. WHO adverse drug event causality assessment criteria, Uppsala drug monitoring centre. 2009;
http://www.who-umc.org/DynPage.aspx?id=22682).

37. Foster BC, Foster MS, Vandenhoek S, Krantis A, Budzinski JW, Arnason JT, Gallicano KD, Choudri $\mathrm{S}$. An in vitro evaluation of human cytochrome $\mathrm{P} 450$ 3A4 and P-glycoprotein inhibition by garlic. J Pharm Pharmaceut Sci, 2001; 4(2):176-184.

38. Le Bloc'h Y, Woggon B, Weissenrieder H, Brawand-Amey M, Spagnoli J, Eap CB, Baumann P. Routine therapeutic drug monitoring in patients treated with 10-360 mg/day citalopram. Ther Drug Monit, 2003; 25(5):600-608.

39. Navarro V, Gastó C, Torres X, Marcos T, Pintor L. Citalopram versus nortriptyline in late-life depression: A 12-week randomized single-blind study. Acta Psych Scand, 2001; 103(6):435-440.

40. Rui Liu, Teresa W. Tam, Jingqin Mao, Ammar Saleem, Anthony Krantis, John T. Arnason, Brian C. Foster. The Effect of Natural Health Products and Traditional Medicines on the Activity of Human Hepatic Microsomal-Mediated Metabolism of Oseltamivir. J Pharm Pharmaceut Sci, 2010; 13(1) $43-55$.

41. Ramírez-Rodríguez G, Vega-Rivera NM, OikawaSala J, Gómez-Sánchez A, Ortiz-López L, EstradaCamarena E. Melatonin synergizes with citalopram to induce antidepressant-like behavior and to promote hippocampal neurogenesis in adult mice. $\mathrm{J}$ Pineal Res, 2014; 56(4):450-461.

42. Sindrup SH, Brosen K, Hansen MG, Aaes-Jorgensen T, Overo KF, Gram LF. Pharmacokinetics of citalopram in relation to the sparteine and the mephenytoin oxidation polymorphisms. Ther Drug Monit, 1993; 15:11-17.

43. Ursing C, Wikner J, Brismar K, Röjdmark S. Caffeine raises the serum melatonin level in healthy subjects: an indication of melatonin metabolism by cytochrome P450(CYP)1A2. J Endocrinol Invest, 2003; 26(5):403-406. 